\title{
Cost-Effectiveness of Targeted Pharmacotherapy for Moderate to Severe Plaque Psoriasis
}

\author{
Nathaniel Hendrix, PharmD; Daniel A. Ollendorf, PhD; Richard H. Chapman, PhD, MS; \\ Anne Loos, MA; Shanshan Liu, MS, MPH; Varun Kumar, MBBS, MPH, MSc; \\ Jeffrey A. Linder, MD, MPH, FACP; Steven D. Pearson, MD, MSc; and David L. Veenstra, PharmD, PhD
}

\begin{abstract}
BACKGROUND: Newer classes of targeted drugs for moderate to severe plaque psoriasis are more effective and more expensive than older classes, posing a difficult and potentially costly decision about whether to use them as initial targeted treatments.
\end{abstract}

OBJECTIVE: To estimate the clinical and economic outcomes of initial targeted treatment for the following drugs: adalimumab, etanercept, and infliximab (TNF $\alpha$ inhibitors); apremilast (PDE4 inhibitor); ustekinumab (IL-12/23 inhibitor); and ixekizumab, secukinumab, and brodalumab (IL-17 inhibitors).

METHODS: We developed a Markov model to simulate patient outcomes as measured by quality-adjusted life-years (QALYs) and health care costs over a 10-year period. We assumed that patients who fail initial targeted treatment either proceed to subsequent therapy or discontinue targeted treatment. Effectiveness estimates for initial treatment were defined as improvement in Psoriasis Area and Severity Index (PASI) from baseline and derived from a 2018 network meta-analysis. Wholesale acquisition drug costs were discounted by a class-specific, empirically derived rebate percentage off of 2016 costs. We conducted one-way and probabilistic sensitivity analyses to assess uncertainty in results.

RESULTS: The incremental benefits compared with no targeted treatment were, in descending order: ixekizumab 1.68 QALYs (95\% credible range $[C R]=1.11-2.02)$, brodalumab 1.64 QALYs $(95 \% \mathrm{CR}=1.08-1.98)$, secukinumab 1.51 QALYs (95\% CR=1.00-1.83), ustekinumab 1.43 QALYs (95\% CR=0.94-1.74), infliximab 1.27 QALYs (95\% CR =0.89-1.55), adalimumab 1.15 QALYs (95\% CR=0.76-1.44), etanercept 0.97 QALYs $(95 \%$ $\mathrm{CR}=0.61-1.25)$, and apremilast 0.87 QALYs $(95 \% \mathrm{CR}=0.52-1.17)$. Costs of care without targeted treatment totaled $\$ 66,451$, and costs of targeted treatment ranged from $\$ 137,080$ (apremilast) to $\$ 255,422$ (ustekinumab). Probabilistic sensitivity analysis results indicated that infliximab and apremilast are likely to be the most cost-effective initial treatments at willingness-to-pay thresholds around $\$ 100,000$ per QALY, while IL-17 drugs are more likely to be cost-effective at thresholds approaching $\$ 150,000$ per QALY. Acquisition cost of the initial targeted drug and utility of clinical response were the most influential parameters.

CONCLUSIONS: Our findings suggest that initial targeted treatment with IL-17 inhibitors is the most effective treatment strategy for plaque psoriasis patients who have failed methotrexate and phototherapy. Apremilast, brodalumab, infliximab, ixekizumab, and secukinumab are cost-effective at different willingness-to-pay thresholds. Additional research is needed on whether the effectiveness of targeted agents changes when used after previously targeted agents.

J Manag Care Spec Pharm. 2018;24(12):1210-17

Copyright $\odot 2018$, Academy of Managed Care Pharmacy. All rights reserved.

\section{What is already known about this subject}

Recent advances in targeted therapy for plaque psoriasis provide significant improvements for patients who have failed phototherapy and methotrexate.

Infliximab is likely to be the most cost-effective TNF alpha inhibitor.

\section{What this study adds}

We found that initial therapy with more effective drugs such as brodalumab, ixekizumab, and secukinumab provides better value than initial therapy with less effective drugs such as adalimumab and etanercept.

At lower willingness-to-pay, apremilast and infliximab were most likely to be cost-effective; at higher willingness-to-pay, brodalumab, ixekizumab, and secukinumab were optimal.

$\mathrm{P}$ laque psoriasis is an autoimmune disease characterized by inflammation of the skin and the formation of red, scaly patches, leading to pain, social difficulties, and loss of function. Moderate to severe plaque psoriasis occurs when psoriatic plaques cover more than $10 \%$ of the body surface area. ${ }^{1}$ Patients with mild plaque psoriasis are usually treated with topical steroids and ultraviolet light therapy (i.e., phototherapy).

For patients with moderate to severe forms of the disease, a mainstay of pharmacological treatment since the 1970s has been immunomodulators, beginning with methotrexate. In the past 20 years, accelerated innovation around biologic agents has added to the immunomodulators available. ${ }^{2}$ Between 1998 and 2008, the tumor necrosis factor alpha (TNFa) inhibitors adalimumab, etanercept, and infliximab were introduced. ${ }^{3-5}$ Ustekinumab, an anti-interleukin (IL) 12 and 23 drug, was approved in 2009. ${ }^{6}$ Apremilast, a phosphodiesterase-4 inhibitor, was approved in 2014 for psoriasis patients who are eligible for biologic treatment, although it is a small-molecule drug. Most recently, 3 IL-17 inhibitors-ixekizumab, secukinumab, and brodalumab-were approved over the past 3 years. ${ }^{8-10}$

Almost all clinical trials of psoriasis treatments estimate effectiveness through a percentage change in the Psoriasis Area and Severity Index (PASI) from baseline. This is a clinicianreported outcome measure that uses percentage of coverage 


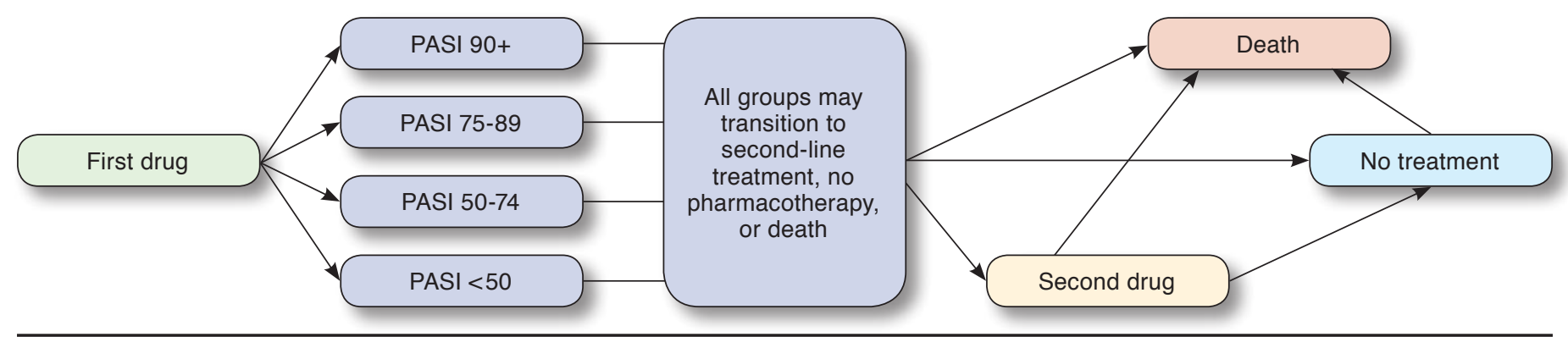

PASI = Psoriasis Area and Severity Index.

and severity (on a 0 to 4 scale) for 4 zones of the body: head, trunk, arms, and legs. ${ }^{11}$ Ideally, treatment eliminates all plaque psoriasis (i.e., produces a 100\% change in PASI score), but a $75 \%$ improvement from baseline (i.e., PASI 75 ) is frequently used as a lower bound for adequate improvement. With TNFa inhibitors, approximately $50 \%$ to $75 \%$ of patients achieve PASI 75. Ustekinumab brings treatment success to about $70 \%$ of patients, while IL-17 drugs have a success rate approaching $90 \%$ with many patients achieving PASI 90 or above. Apremilast is successful for about $30 \%$ of patients but is the only oral therapy approved for moderate to severe plaque psoriasis; all others require subcutaneous or intravenous administration.

While newer drugs have expanded treatment options, their use has become a significant driver of costs for payers. ${ }^{12}$ Payers and developers of clinical guidelines must decide whether to prioritize initial targeted treatment with these newer classes of targeted therapy over the older, less expensive targeted therapies. The objective of this analysis was to estimate the relative effectiveness and cost-effectiveness of initial treatment with targeted therapies for moderate to severe plaque psoriasis to inform prescribing, clinical guidelines, and coverage decisions.

\section{Methods}

\section{Model Description}

We developed a Markov model with 7 health states, as shown in Figure 1. At the start of therapy, patients respond to treatment by entering 1 of 4 PASI response levels-PASI 90 and higher, PASI 75-89, PASI 50-74, and PASI $<50$. Since our drugs of interest are usually reserved for patients who have failed topical drugs, phototherapy, and methotrexate, we included only targeted drugs in the model. Treatment with each drug begins with an initiation period, defined as the point in time at which the primary trial outcome was measured in each drug's pivotal trials. This period lasts 16 weeks for adalimumab and apremilast, 10 weeks for infliximab, and 12 weeks for all other targeted agents.
Patients who have a PASI response less than $75 \%$ during the initiation period discontinue initial targeted therapy. As patients withdraw from their first targeted treatment for any reason, they can transition to secondary targeted therapy or to no treatment. Secondary therapy for anti-TNFa drugs comprised the 3 IL-17 drugs plus ustekinumab; for all other drugs, secondary therapy included only IL-17 drugs. If patients fail secondary therapy, they transition to no active treatment.

Limiting ourselves to 2 lines of targeted therapy in our model may not reflect how recent drug approvals have expanded the number of options available to patients failing 1 or 2 lines of therapy. However, modeling these subsequent lines of treatment would have diminished the importance of the initial choice of targeted treatment, which is the biggest concern for payers and prescribers.

We followed these hypothetical patients for 10 years rather than for their lifetime to capture the effect of initial treatment and to facilitate comparison with previous economic evaluations. ${ }^{13-15}$ Patients could transition between states every month. To allow our study to be relevant to coverage decisions, we used a payer perspective and, therefore, considered direct medical costs only. We built the model as an Excel spreadsheet (Microsoft, Redmond, WA).

\section{Model Assumptions}

Current literature does not support a complete characterization of treatment patterns for plaque psoriasis. For aspects that are currently unknown, we made the following assumptions based on simplicity and validity in light of existing evidence:

1. A patient cannot transition between levels of PASI improvement. No published evidence suggests that drug response improves past the initiation period. Meanwhile, fading response over time is accounted for in the discontinuation rate, which is primarily drug specific.

2. In the absence of drug-specific evidence, we assumed that the discontinuation rate for the 3 newest drugs (ixekizumab, secukinumab, and brodalumab) is the same as ustekinumab. This is evaluated in the sensitivity analyses. 
Cost-Effectiveness of Targeted Pharmacotherapy for Moderate to Severe Plaque Psoriasis

TABLE 1 Base-Case Estimates of Cost, QALYs, and Incremental Cost-Effectiveness with 10-Year Time Horizon

\begin{tabular}{|c|c|c|c|c|}
\hline & Cost, \$ & QALYs & ICER, \$/QALY & ICER vs. Etanercept, \$/QALY \\
\hline No treatment & 66,451 & 5.531 & N/A & N/A \\
\hline Apremilast & 137,080 & 6.403 & 81,033 (vs. no treatment) & N/A \\
\hline Etanercept & 181,387 & 6.505 & 433,248 (vs. apremilast) & N/A \\
\hline Adalimumab & 194,180 & 6.681 & 72,703 (vs. etanercept) & 72,703 \\
\hline Infliximab & 176,695 & 6.804 & Dominant & Dominant \\
\hline Ustekinumab & 255,422 & 6.959 & Dominated & 162,923 \\
\hline Secukinumab & 208,727 & 7.045 & 132,913 (vs. infliximab) & 50,661 \\
\hline Brodalumab & 236,690 & 7.173 & 217,589 (vs. secukinumab) & 82,766 \\
\hline Ixekizumab & 243,938 & 7.208 & 208,872 (vs. brodalumab) & 88,991 \\
\hline
\end{tabular}

ICER = incremental cost-effectiveness ratio; N/A = not applicable; $Q A L Y=$ quality-adjusted life-year.

3. Upon discontinuation from a given initial drug, half of patients begin secondary therapy while half discontinue treatment. This decision was made based on 2 claims-based studies that found use of a subsequent therapy to be between $37 \%$ and $50 \%{ }^{16,17}$

4. Risk of death is based on age alone and is not modified by the psoriasis-related state of health, as no robust evidence has found that modification of psoriasis-related health state modifies a patient's risk of death. Patients in this model begin treatment at age 45 years, which is estimated from the studies included in our meta-analysis.

5. Patients use initial targeted therapy throughout the entire initiation period, as the drug's efficacy cannot be evaluated before the end of this period.

6. To reflect current clinical practice, we assumed that subcutaneous drugs are administered in clinic the first time and by the patient themselves thereafter.

\section{Drug Effectiveness and Durability}

As detailed in a separate study, we conducted a Bayesian network meta-analysis of 36 trials (34 of which were phase 3) that used PASI score as their endpoint in order to generate comparisons for each of the agents of interest; in-depth methods and findings from this evaluation are available elsewhere. ${ }^{18,19}$ We adjusted for the placebo response rate in each study to account for unobserved variability in patient populations.

The network meta-analysis showed that all immunomodulators were statistically superior to placebo. In head-to-head comparisons, ixekizumab had the highest relative effectiveness. In descending order of effectiveness, ixekizumab was followed by brodalumab, infliximab, secukinumab, ustekinumab, adalimumab, etanercept, and apremilast. These results are consistent with the few direct comparative trials that have been published, which showed that ustekinumab, secukinumab, and ixekizumab had higher efficacy than etanercept, ${ }^{20-22}$ and that all IL-17 drugs had higher efficacy than ustekinumab. ${ }^{23-25}$

We derived the drug-specific first-year discontinuation rates from a retrospective claims analysis of 4,309 psoriasis patients from 2007 through 2012. ${ }^{26}$ Most patients received etanercept or adalimumab, with a small number $(n=195)$ receiving ustekinumab. Over the follow-up period, 35\%, 27\%, and 16\% of patients on etanercept, adalimumab, and ustekinumab, respectively, discontinued therapy. We assumed the discontinuation rate for apremilast was the same as for etanercept, and that ixekizumab, secukinumab, and brodalumab had the same rate as ustekinumab (16\%).

Discontinuation rates after the first year were based on a long-term Danish cohort study. ${ }^{27}$ The study evaluated 1,867 courses of treatment (adalimumab $n=774$, etanercept $n=449$, infliximab $n=253$, ustekinumab $n=391$ ) administered to 1,277 patients for up to 10 years. Based on the results of this study, we estimated that $15 \%$ of adalimumab, etanercept, and infliximab patients discontinued treatment each subsequent year, while 5\% of ustekinumab patients did. This study's analysis of patients who previously received a targeted treatment also informed our estimation of the discontinuation rate from secondary therapy to no treatment at $10 \%$ per year. Based on a 2016 study suggesting that secukinumab patients who initially respond maintain that response up to 4 years, we assumed that all IL-17 drugs have the same 5\% discontinuation rate as ustekinumab. ${ }^{28}$ We also assumed, based on this study, that the first-year discontinuation rate of infliximab is the same as adalimumab at $27 \%$.

\section{Health-State Utilities}

Quality of life estimates in the form of health-state utilities were based on 4 levels of percentage of improvement in PASI score, regardless of drug: 90-100, 75-89, 50-74, and 0-50. The option of no pharmaceutical treatment is assumed to have the same utility as baseline or pretreatment status.

Utilities for the base-case scenario were obtained from an analysis of EQ-5D data in 3,231 patients enrolled in 5 randomized controlled trials evaluating secukinumab in moderate to severe plaque psoriasis. ${ }^{29}$ The EQ-5D was measured alongside PASI in the secukinumab trials, and the improvement in PASI score was mapped onto the EQ-5D, resulting in a utility of 
0.906 for PASI $90-100,0.868$ for PASI $75-89,0.835$ for PASI $50-74$, and 0.751 for PASI improvement of less than $50 \%$. The utility for patients not receiving any targeted agent was 0.642 , based on this study's estimate of its population's baseline (i.e., untreated) utility.

The utility of secondary therapy was calculated based on estimated response across selected targeted therapies. Based on observed differences in response between biologic-naive and nonnaive patients in the ustekinumab and secukinumab clinical trials, we assumed secondary treatment had a 10\% absolute lower probability of achieving PASI 75.28,30,31 For each secondary drug, we applied a 5\% decrease in the probability of both PASI 90 and PASI 75-89, and a 5\% increase in the probabilities of PASI $<50$ and PASI 50-74. We then calculated the utility for each included secondary drug and averaged across them.

Due to similar adverse event profiles between drugs and the absence of their utility evaluation in other cost-effectiveness analyses in psoriasis, we did not include any adverse eventassociated disutilities. We expect that inclusion of these disutilities would not have a meaningful effect on results given the low rate of serious adverse events for the drugs evaluated in this study. That said, brodalumab was given a "black box" warning for suicidality. ${ }^{10}$ In acknowledgement of the severity of this adverse event, we performed sensitivity analyses to show the effect of its inclusion.

\section{Costs}

Briefly, we calculated drug costs by applying an empirically derived, class-specific discount to the list price of each drug by comparing net price and wholesale acquisition cost (WAC) over 1 year, ${ }^{32}$ then averaging the difference within each drug class for each quarter and rounding to the nearest $5 \%$. Because it was released less than a year ago, we used a point estimate of brodalumab WAC with its own rebate percentage taken from private communication with the manufacturer. Administration costs were based on 2016 Medicare reimbursement rates. Since we took a payer perspective, the cost of lost productivity due to illness or medical appointments was not included. Total treatment costs were summed over 10 years using a 3\% annual discount rate. A more detailed explanation of costs can be found in Appendix A (available in online article).

\section{Sensitivity Analysis}

We conducted a probabilistic sensitivity analysis using 5,000 runs of a Markov chain Monte Carlo simulation. This produced a distribution of credible outcomes by systematically varying the model's parameters according to the ranges and distributions listed in Appendix B (available in online article). We produced a cost-effectiveness acceptability curve from these data by graphing the probability that each drug has the highest net monetary benefit at a given willingness to pay per qualityadjusted life-year (QALY).
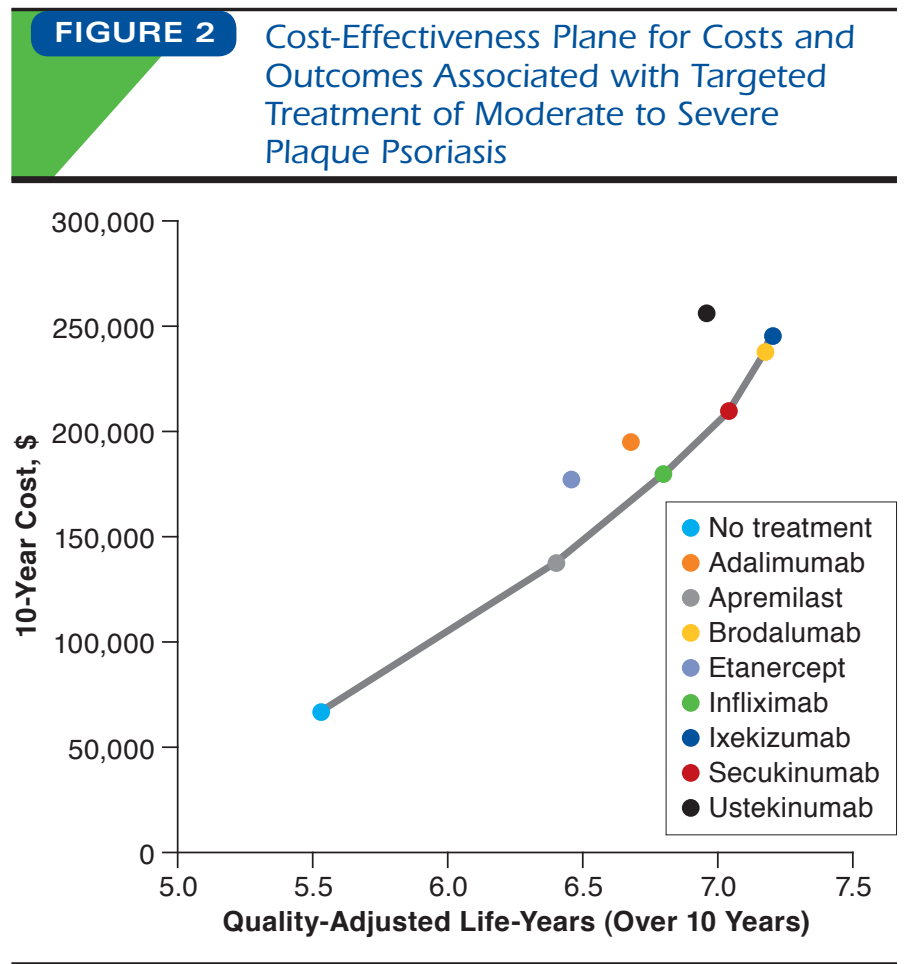

Note: The solid line represents the cost-effectiveness frontier.

We also conducted one-way sensitivity analyses of initial ixekizumab versus initial etanercept. This comparison was chosen to reflect the policy question of whether highly effective IL-17 drugs should be preferred as initial treatment over TNFa drugs, to demonstrate drivers of value, and because the comparison of brodalumab versus etanercept was more complex since brodalumab dominated (less expensive and more effective) etanercept in some analyses.

\section{Results}

In the base case, the most effective treatment is ixekizumab with 7.208 QALYs, followed by brodalumab with 7.173 QALYs. Apremilast and etanercept are the least effective treatments, with 6.403 and 6.505 QALYs, respectively.

The least expensive initial treatment strategies were apremilast $(\$ 137,080)$ and infliximab $(\$ 176,695)$. The most expensive treatments were ixekizumab and ustekinumab, which cost $\$ 243,938$ and $\$ 255,422$, respectively. Table 1 contains complete results for all 8 drugs, and Figure 2 shows their results mapped onto the cost-effectiveness plane.

Our probabilistic sensitivity analysis indicated that apremilast and infliximab are likely to provide the most net monetary benefit at willingness-to-pay (WTP) thresholds near $\$ 100,000$ (Figure 3). The 3 modeled IL-17 drugs are likely to provide the most net monetary benefit at higher WTP thresholds approaching $\$ 150,000$ per QALY. 


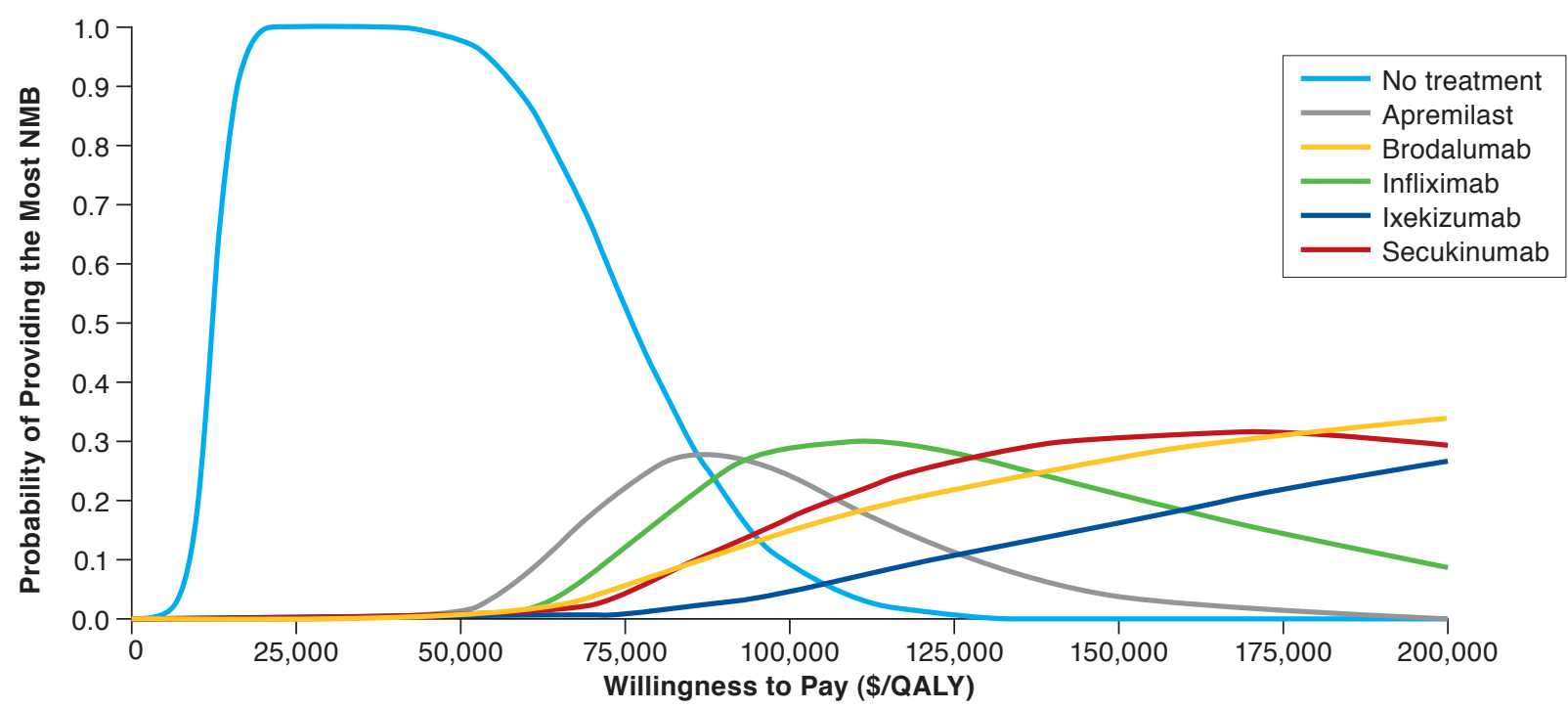

${ }^{a}$ Adalimumab, etanercept, and ustekinumab are not pictured because they have $<1 \%$ probability of providing the most NMB at any willingness to pay. $N M B=$ net monetary benefit; $Q A L Y=$ quality-adjusted life-years.

We also calculated incremental cost-effectiveness ratios (ICERs) for etanercept compared with all drugs with superior efficacy (Table 1). We selected these comparisons because etanercept is the only biologic drug for which we had adequate evidence to distinguish its effectiveness from all other drugs in the model. In the base case, ICERs range from $\$ 50,661$ per incremental QALY for secukinumab to $\$ 162,923$ per QALY for ustekinumab. Notably, infliximab dominated etanercept (i.e., produced more QALYs at lower cost), and all IL-17 drugs had ICERs under \$100,000 per QALY when compared with etanercept.

The results of the one-way sensitivity analysis of ixekizumab versus etanercept showed that the most influential parameters were the utility of treatment success and the price of both treatment options (Figure 4). Notably, the effectiveness of secondary therapy was also somewhat influential and was a highly uncertain parameter. The conclusions of the base-case analysis-that etanercept is a less expensive but less effective treatment-were robust to all changes made during the oneway sensitivity analysis.

\section{Discussion}

Our evaluation of the cost-effectiveness of 8 targeted drugs for the treatment of moderate to severe plaque psoriasis can inform the development of payer formularies and professional society guidelines. In the U.S. setting, our results suggest that the most effective initial targeted treatment strategy for patients who have failed methotrexate, phototherapy, and topical treatment is the use of IL-17 inhibitors, and these drugs were likely cost-effective at higher WTP thresholds. Apremilast and infliximab-the 2 least expensive drugs in our analysis-were likely to provide cost-effective treatment, although they provide adequate response for fewer people than the IL-17 drugs.

More generally, each of the drugs in this analysis provide good value when compared with nontargeted treatment. Given their effectiveness, the class of IL-17 drugs in particular shows good value. While these drugs tend to be expensive, their higher overall effectiveness leads to fewer patients incurring the cost of loading doses with secondary therapy or lack of benefit through treatment discontinuation. In other words, we found that the use of an effective secondary "rescue" drug does not necessarily offset the loss of value from a less effective initial drug, especially in the case of adalimumab and etanercept. This is a noteworthy result, as most cases of step therapy prioritize the initial use of an older, less costly therapy before proceeding to newer agents.

Despite the cost-effectiveness of the IL-17 drugs, there are reasons for policymakers to consider keeping drugs from other classes in their formularies. IL-17 inhibitors are contraindicated for some patients; for example, patients with inflammatory bowel disease cannot use either ixekizumab or secukinumab. "Brodalumab, as previously stated, is unique in having a "black box" warning for suicidality. Given its trial's observed suicide rate of $0.09 \%$ (4 per 4,464 patients), ${ }^{10}$ we calculated that this would, in the most pessimistic case, reduce the number of QALYs gained by brodalumab over 10 years by 0.005 . This does not change our conclusion about 
Ixekizumab price $(\$ 2,145, \$ 3,218)$

Utility of PASI $75 \& 90(-0.05,+0.05)$

Etanercept price $(\$ 574, \$ 861)$

Cost of $2 \mathrm{~L}(-20 \%,+20 \%)$

Utility on $2 \mathrm{~L}(-0.05,+0.05)$

$1 \mathrm{~L} \mathrm{~d} / \mathrm{c}$ rate (year>1, PASI 75+) [ixek.] $(2.5 \%, 10 \%)$

Probability of PASI 75 [etan.] (43\%, 53\%)

Probability of PASI 75 [ixek.] (82\%, 92\%)

$1 \mathrm{~L} \mathrm{~d} / \mathrm{c}$ rate (year $>1$, PASI $75+$ ) [etan.] $(10 \%, 20 \%)$

d/c \% to $2 \mathrm{~L}(25 \%, 75 \%)$

Annual $2 \mathrm{~L} \rightarrow$ no treatment $(5 \%, 15 \%)$

Utility of PASI $<75(-5 \%,+5 \%)$

$1 \mathrm{~L} \mathrm{~d} / \mathrm{c}$ rate (year 1, PASI 75+) [ixek.] (12\%, 20\%)

$1 \mathrm{~L} \mathrm{~d} / \mathrm{c}$ rate (year 1, PASI $75+$ ) [etan.] (30\%, 40\%)

Discount rate $(0 \%, 5 \%)$

Cost per in-clinic sub-q inj (\$20.35, \$30.53)

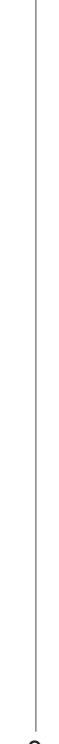

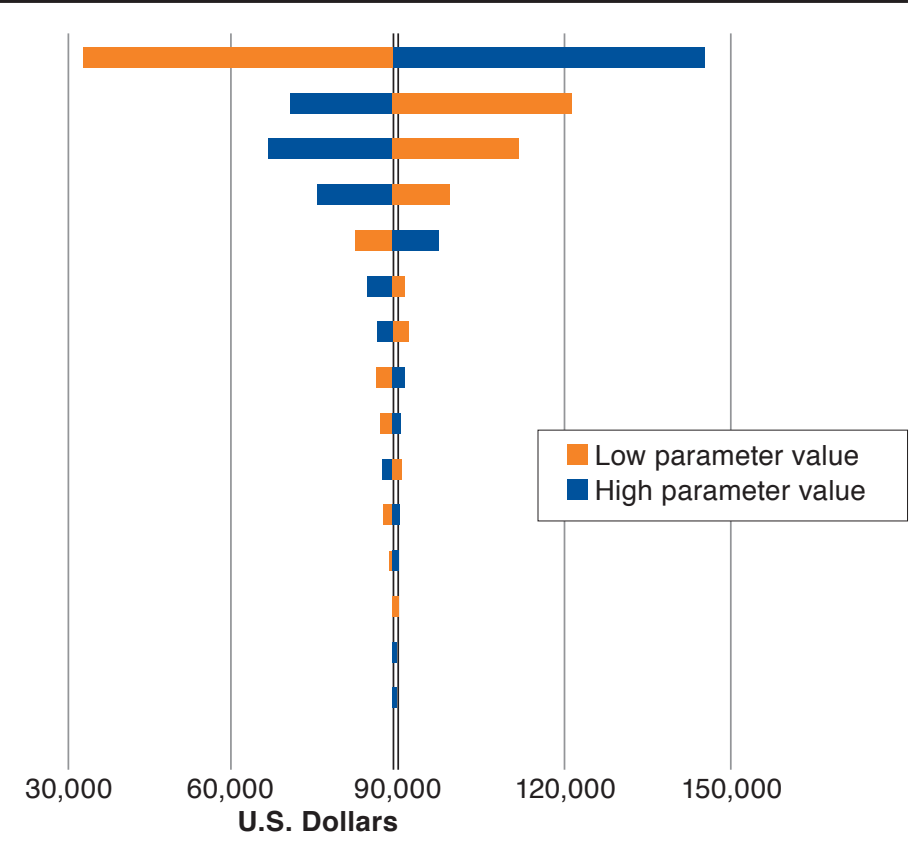

U.S. Dollars

$2 \mathrm{~L}=$ secondary treatment; $\mathrm{d} / \mathrm{c}=$ discontinuation; etan=etanercept; ixek=ixekizumab; PASI= percentage of change in Psoriasis Area and Severity Index; sub- $q$ inj $=$ subcutaneous injection.

brodalumab's cost-effectiveness, but it reinforces the point that several treatment options should be offered for patients with contraindications to an IL-17 drug.

The other 2 cost-effective treatments, apremilast and infliximab, have disadvantages as well. Apremilast is dosed twice daily, which may lead to difficulties with adherence. Infliximab requires a 2-hour intravenous administration and carries with it the highest risk of upper respiratory tract infection of any drug considered here.

Several previous studies of the cost-effectiveness of targeted therapies for plaque psoriasis have been published, although use of the U.S. setting has been less common. Our study is unique in its inclusion of the 2 most recently approved IL-17 drugs and apremilast. Studies corroborating our assessment of the relative cost-effectiveness of the TNFa drugs have been conducted in the United States and Germany. ${ }^{33-35}$

While the TNFa drugs have been analyzed in several settings, other classes are poorly represented in the peer-reviewed cost-effectiveness literature. One published analysis including IL-17 and IL-12/23 drugs found that secukinumab dominates ustekinumab, adalimumab, and etanercept in the Canadian health care setting. ${ }^{36}$ Another abstract from Italy concurred with the findings of the Canadian abstract. ${ }^{37}$ While these results do not exactly match our findings because of differences in cost, the ordering of the drugs by cost-effectiveness was comparable to our study.

\section{Limitations}

The results of this study must be interpreted considering its uncertainties. We lacked information regarding patterns of initial and secondary targeted treatments in plaque psoriasis patients. Our study was further limited by the difficulty of mapping PASI values onto utility (quality of life) values. The utility of PASI response also depends on baseline PASI, which has not been explicitly considered in the mapping study we used as our source for utility weights, nor in any other published study. Rather than using PASI as a surrogate for well-being, we would have preferred to use utilities directly elicited from patients taking these medications. Although they were gathered in some trials, these data have not been made available.

Most importantly, our study was limited by a lack of information about how efficacy changes between first and subsequent targeted therapy. Specifically, the effectiveness of subsequent therapy was an important factor in the cost-effectiveness of ixekizumab compared with etanercept, although price of the initial drug was most important. We have estimated the likely decrease in effectiveness between first- and second-line targeted treatment from clinical trials that compared efficacy in biologic-naive versus nonnaive patients, but this is a highly complex topic with significant, poorly characterized variability between drugs. 
One important area for future research will be the effect on price of biosimilars for these drugs. Infliximab is the only drug in this analysis with biosimilars on the market, though adalimumab and etanercept biosimilars have been approved by the U.S. Food and Drug Administration. The response to this approval is notable, though, because the price of branded infliximab has been decreased such that its net price is lower than its biosimilars. ${ }^{32}$ If wider release of biosimilars further decreases prices, reconsideration of our current conclusions will be warranted.

\section{Conclusions}

The results of our study suggest that initial treatment with IL-17 drugs is the most effective strategy and is likely to be cost-effective at WTP thresholds approaching $\$ 150,000$ per QALY. At lower thresholds, apremilast and infliximab are likely to be the most cost-effective initial targeted treatments. As more targeted drugs for plaque psoriasis are approved, it will become vital to fill the gap in knowledge that exists around the effect of an initial targeted treatment on the efficacy of subsequent targeted drugs.

\section{Authors}

NATHANIEL HENDRIX, PharmD, and DAVID L. VEENSTRA, PharmD, PhD, Comparative Health Outcomes, Policy, and Economics (CHOICE) Institute, University of Washington, Seattle. DANIEL A. OLLENDORF, PhD; RICHARD H. CHAPMAN, PhD, MS; ANNE LOOS, MA; SHANSHAN LIU, MS, MPH; VARUN KUMAR, MBBS, MPH, MSC; and STEVEN D. PEARSON, $M D, M S c$, Institute for Clinical and Economic Review, Boston, Massachusetts. JEFFREY A. LINDER, MD, MPH, FACP, Division of General Internal Medicine and Geriatrics, Northwestern University Feinberg School of Medicine, Chicago, Illinois.

AUTHOR CORRESPONDENCE: David L. Veenstra, PharmD, PhD, Professor and Associate Director, Comparative Health Outcomes, Policy, and Economics (CHOICE) Institute, University of Washington Department of Pharmacy, Seattle, WA 98195. E-mail: veenstra@uw.edu.

\section{DISCLOSURES}

Funding for this study was contributed by the Institute for Clinical and Economic Review (ICER). Ollendorf, Chapman, Pearson, and Kumar are current employees, and Loos and Liu are former employees, of ICER, an independent organization that evaluates the evidence on the value of health care interventions, which is funded by grants from the Laura and John Arnold Foundation, Blue Shield of California Foundation, and the California HealthCare Foundation.

ICER's annual policy summit is supported by dues from Aetna, AHIP, Anthem, Alnylam, AstraZeneca, Blue Shield of California, Cambia Health Solutions and MedSavvy, CVS Caremark, Editas, Express Scripts, Genentech, GlaxoSmithKline, Harvard Pilgrim Health Care, Health Care Service Corporation, OmedaRx, United Healthcare, Johnson \& Johnson, Kaiser Permanente, Premera Blue Cross, Merck, National Pharmaceutical Council, Takeda, Pfizer, Novartis, Lilly, Humana, Prime Therapeutics, Sanofi, and Spark Therapeutics.
Linder owns stock in Amgen, Biogen, and Eli Lilly; has contingent value rights in Sanofi Genzyme (related to alemtuzumab for multiple sclerosis); has received grant support from Astellas Pharma not related to this study and Clintrex, which was supported by AstraZeneca on an unrelated topic; and has received an honorarium from the Society of Healthcare Epidemiology of America (SHEA) as part of the SHEA Antimicrobial Stewardship Research Workshop Planning Committee, an educational activity supported by Merck. No other authors have potential conflicts of interest.

\section{REFERENCES}

1. Mrowietz U, Kragballe K, Reich K, et al. Definition of treatment goals for moderate to severe psoriasis: a European consensus. Arch Dermatol Res. 2011;303(1):1-10.

2. Menter A, Gottlieb A, Feldman SR, et al. Guidelines of care for the management of psoriasis and psoriatic arthritis. J Am Acad Dermatol. 2008;58(5):826-50.

3. Humira (adalimumab) injection, for subcutaneous use. AbbVie. September 2018. Available at: https://www.rxabbvie.com/pdf/humira.pdf. Accessed October 4, 2018.

4. Fisher RS, Nune G, Roberts SE, Cramer JA. The Personal Impact of Epilepsy Scale (PIES). Epilepsy Behav. 2015;42:140-46.

5. Remicade (infliximab) lyophilized concentrate for injection, for intravenous use. Janssen Biotech. June 2018. Available at: http://www.janssenlabels.com/package-insert/product-monograph/prescribing-information/ REMICADE-pi.pdf. Accessed October 4, 2018.

6. Stelara (ustekinumab) injection, for subcutaneous or intravenous use Janssen Biotech. June 2018. Available at: http://www.janssenlabels.com/ package-insert/product-monograph/prescribing-information/STELARA-pi. pdf. Accessed October 4, 2018.

7. Otezla (apremilast) tablets, for oral use. Celgene Corporation. June 2017. Available at: http://www.celgene.com/content/uploads/otezla-pi.pdf. Accessed October 4, 2018.

8. Taltz (ixekizumab) injection, for subcutaneous use. Eli Lilly and Company. May 2018. Available at: http://uspl.lilly.com/taltz/taltz.html\#pi. Accessed October 4, 2018.

9. Cosentyx (secukinumab) injection, for subcutaneous use. Novartis Pharmaceutical Corporation. June 2018. Available at: https://www.pharma. us.novartis.com/sites/www.pharma.us.novartis.com/files/cosentyx.pdf. Accessed October 4, 2018.

10. Siliq (brodalumab) injection, for subcutaneous use. Valeant Pharmaceuticals. February 2017. Available at: http://www.valeant.com/ Portals/25/Pdf/PI/Siliq-pi.pdf. Accessed October 4, 2018.

11. Feldman S, Krueger G. Psoriasis assessment tools in clinical trials. Ann Rheum Dis. 2005;64(Suppl 2):ii65-ii68.

12. Brezinski EA, Dhillon JS, Armstrong AW. Economic burden of psoriasis in the United States. JAMA Dermatol. 2015;151(6):651-58.

13. Pan F, Brazier NC, Shear NH, Jivraj F, Schenkel B, Brown R. Cost utility analysis based on a head-to-head phase 3 trial comparing ustekinumab and etanercept in patients with moderate to severe plaque psoriasis: a Canadian perspective. Value Health. 2011;14(5):652-56.

14. Knight C, Mauskopf J, Ekelund M, Singh A, Yang S, Boggs R. Costeffectiveness of treatment with etanercept for psoriasis in Sweden. Eur J Health Econ. 2012;13(2):145-56.

15. Woolacott N, Hawkins NS, Mason A, et al. Etanercept and efalizumab for the treatment of psoriasis: a systematic review. Health Technol Assess. 2006;10(46):1-233, i-iv

16. Doshi JA, Takeshita J, Pinto L, et al. Biologic therapy adherence, discontinuation, switching, and restarting among patients with psoriasis in the U.S. Medicare population. J Am Acad Dermatol. 2016;74(6):1057-65.e4. 
17. Foster SA, Zhu B, Guo J, et al. Patient characteristics, health care resource utilization, and costs associated with treatment-regimen failure with biologics in the treatment of psoriasis. J Manag Care Spec Pharm. 2016;22(4):396-405. Available at: https://www.jmcp.org/doi/10.18553/ jmcp.2016.22.4.396.

18. Institute for Clinical and Economic Review. Final evidence report: targeted immunomodulators for the treatment of moderate-severe plaque psoriasis. December 2, 2016. Available at: https://icer-review.org/wp-content/ uploads/2016/11/NE_CEPAC_Psoriasis_Evidence_Report_FINAL_012317. pdf. Accessed October 4, 2018.

19. Loos AM, Liu S, Segel C, Ollendorf DA, Pearson SD, Linder JA. Comparative effectiveness of targeted immunomodulators for the treatment of moderate to severe plaque psoriasis: a systematic review and network meta-analysis. J Am Acad Dermatol. 2018;79(1):135-44.e7.

20. Griffiths CE, Reich K, Lebwohl M, et al. Comparison of ixekizumab with etanercept or placebo in moderate to severe psoriasis (UNCOVER-2 and UNCOVER-3): results from two phase 3 randomised trials. Lancet. 2015;386(9993):541-51.

21. Griffiths CEM, Strober BE, van de Kerkhof P, et al. Comparison of ustekinumab and etanercept for moderate to severe psoriasis. N Engl J Med. 2010;362(2):118-28.

22. Langley RG, Elewski BE, Lebwohl M, et al. Secukinumab in plaque psoriasis — results of two phase 3 trials. N Engl J Med. 2014;371(4):326-38.

23. Thaçi D, Blauvelt A, Reich K, et al. Secukinumab is superior to ustekinumab in clearing skin of subjects with moderate to severe plaque psoriasis: CLEAR, a randomized controlled trial. J Am Acad Dermatol. 2015;73(3):400-09.

24. Lebwohl M, Strober B, Menter A, et al. Phase 3 studies comparing brodalumab with ustekinumab in psoriasis. N Engl J Med. 2015;373(14):1318-28.

25. McNamara D. Head-to-head results compare biologics for psoriasis. Medscape. October 5, 2016. Available at: https://www.medscape.com/viewarticle/869842. Accessed October 4, 2018.

26. Feldman SR, Zhao Y, Shi L, Tran MH, Lu J. Economic and comorbidity burden among moderate to severe psoriasis patients with comorbid psoriatic arthritis. Arthritis Care Res (Hoboken). 2015;67(5):708-17.

27. Gniadecki R, Bang B, Bryld LE, Iversen L, Lasthein S, Skov L. Comparison of long-term drug survival and safety of biologic agents in patients with psoriasis vulgaris. Br J Dermatol. 2015;172(1):244-52.

28. Bissonnette R, Luger T, Thaçi D, et al. Secukinumab maintains high levels of efficacy through 3 years of treatment: results from an extension to a phase 3 study (sculpture). Australas J Dermatol. 2016;57:39.

29. National Institute for Health and Care Excellence. Secukinumab for treating moderate to severe plaque psoriasis: guidance and guidelines. July 22, 2015. Available at: https://www.nice.org.uk/guidance/ta350. Accessed October 4, 2018.
30. Papp K, Gottlieb AB, Naldi L, et al. Safety surveillance for ustekinumab and other psoriasis treatments from the psoriasis longitudinal assessment and registry (PSOLAR). J Drugs Dermatol. 2015;14(7):706-14.

31. Griffiths C, Papp K, Zaldivar ER, et al. Secukinumab shows efficacy in subjects regardless of previous exposure to biologic therapy: a pooled subanalysis from four phase 3 clinical trials in psoriasis. J Am Acad Dermatol. 2015;72(5):AB251.

32. SSRHealth. US brand Rx net price. Research archive. Retrieved June 1, 2018. Available at: http://www.ssrhealth.com/research-archive/. Accessed October 4, 2018.

33. Nelson AA, Pearce DJ, Fleischer AB, Balkrishnan R, Feldman SR. Costeffectiveness of biologic treatments for psoriasis based on subjective and objective efficacy measures assessed over a 12-week treatment period. J Am Acad Dermatol. 2008;58(1):125-35.

34. Ahn CS, Gustafson CJ, Sandoval LF, Davis SA, Feldman SR. Cost effectiveness of biologic therapies for plaque psoriasis. Am J Clin Dermatol. 2013;14(4):315-26.

35. Schmitt-Rau K, Rosenbach T, Radtke MA, Augustin M. Costeffectiveness of biological therapy in remission induction of moderate to severe plaque psoriasis. Dermatology. 2010;221(3):236-42.

36. Lee A, Gregory V, Gu Q, Becker DL, Barbeau M. Cost-effectiveness of secukinumab compared to current treatments for the treatment of moderate to severe plaque psoriasis in Canada. Value Health. 2015;18(3):A182.

37. D'Ausilio A, Aiello A, Daniel F, Graham C, Roccia A, Toumi M. PSS50A cost-effectiveness analysis of secukinumab $300 \mathrm{mg}$ vs current therapies for the treatment of moderate to severe plaque psoriasis in Italy. Value Health. 2015;18(7):A424 [abstract].

38. Yu AP, Tang J, Xie J, et al. Economic burden of psoriasis compared to the general population and stratified by disease severity. Curr Med Res Opin. 2009;25(10):2429-38

39. Truven Health Analytics, IBM Watson Health. Micromedex RED BOOK Online. Database. Retrieved June 1, 2018. Available at: http://truvenhealth. com/Products/Micromedex/Product-Suites/Clinical-Knowledge/RED-BOOK. Accessed October 4, 2018

40. Ibrahim G, Waxman R, Helliwell PS. The prevalence of psoriatic arthritis in people with psoriasis. Arthritis Rheum. 2009;61(10):1373-78.

41. Centers for Medicare \& Medicaid Services. FY 2017 final rule and correction notice tables. Retrieved April 16, 2018. Available at: https://www. cms.gov/Medicare/Medicare-Fee-for-Service-Payment/AcuteInpatientPPS/ FY2017-IPPS-Final-Rule-Home-Page-Items/FY2017-IPPS-Final-Rule-Tables. html. Accessed October 4, 2018.

42. Hankin CS, Feldman SR, Szczotka A, Stinger RC, Fish LS, Hankin DL. A cost comparison of treatments of moderate to severe psoriasis. Drug Benefit Trends. 2005;17:200-14

43. Eckman MH, Kaiser TE, Sherman KE. The cost-effectiveness of screening for chronic hepatitis B infection in the United States. Clin Infect Dis. 2011;52(11):1294-306. 
We divided monthly costs into those of drug acquisition, administration, clinic visits, and laboratory tests. Costs for adverse events were included only in sensitivity analyses.

Each cycle, every surviving patient on pharmacotherapy was assumed to consume an amount of drug equal to the monthly dosage for that drug (or the average monthly dosage for the drugs chosen as secondary therapy). While the wholesale acquisition cost (WAC) of drugs is commonly used in cost-effectiveness analyses, we obtained data from SSRHealth on net pricing (discounts, rebates, concessions to wholesalers and distributors, and patient assistance programs) for each unit of drug across all payer types. ${ }^{32}$ We estimated net prices for these drugs by comparing the rolling averages of both net prices and WAC prices per unit over 1 year (4Q2015 to 3Q2016) to arrive at an average discount from WAC. We calculated averages by drug class and rounded these to the nearest 5\%. Finally, we applied the drug class average to the most current WAC price for each medication to arrive at an estimated net price. The class discount was 30\% for TNF $\alpha$ drugs, $40 \%$ for IL-17 drugs other than brodalumab, 15\% for ustekinumab, and 20\% for apremilast. Because it has been on the market for a shorter period of time than the other drugs, we used a point estimate of brodalumab's WAC and applied to it a $20 \%$ rebate obtained via private communication.

Infliximab and ustekinumab are dosed based on body weight. We assumed that each infliximab administration used five $100 \mathrm{mg}$ vials to account for drug wastage because of incomplete vial use. Based on weight distribution data from the ustekinumab trials, we assumed that $30 \%$ of patients weighed more than $100 \mathrm{~kg}$ and, therefore, would receive $90 \mathrm{mg}$ rather than the standard $45 \mathrm{mg}$ dose.

Infliximab is unique in that it is the only drug included in this analysis with biosimilars on the market. Biosimilars are expected to reduce the price of drugs, and that is also the case with infliximab. Our finding is that the net price of branded infliximab has been reduced to a point lower than the net price of infliximab biosimilars.

The cost of secondary targeted therapy was calculated as the average of all included therapies. As described above in our modeling approach, this assumption was necessary to reflect the real-world practice of treatment switching yet accommodate the complete lack of data on the safety and effectiveness of specific secondary treatment scenarios. A switching cost was assigned to the first month of secondary therapy to reflect the additional cost of initiation above and beyond maintenance therapy, based on the average incremental cost of the induction period across included drugs.
The cost of no pharmacotherapy was derived from a study of 2003 claims data by Yu et al. (2009). ${ }^{38}$ The study found a total of $\$ 5,586$ (2007 U.S. dollars) in nondrug costs, such as hospitalization, for patients with moderate to severe plaque psoriasis, which we adjusted to 2016 U.S. dollars using the medical consumer price index. All drug acquisition costs can be found in the table below.

Infliximab, the only drug in the analysis that requires intravenous administration, is delivered over a 2-hour infusion. Each administration was assumed to cost $\$ 164.54$ : $\$ 136.15$ for the first hour (Current Procedural Terminology [CPT] code 96413) and $\$ 28.39$ for the second hour (CPT code 96415). We assumed that the first administration of subcutaneous drugs would be administered at a clinic. The cost of this service, obtained from RED BOOK Online (CPT code 96372), was $\$ 25.44 .{ }^{39}$ There were no administration costs for the only oral medication in the analysis, apremilast. As all secondary drugs were administered subcutaneously, we included the cost of a single in-clinic subcutaneous injection in the cost of switching to secondary treatment.

Due to the interaction of the targeted therapies with the immune system, many psoriasis patients require screening and monitoring for potential infection. Some also require testing of physiologic systems, such as hepatic function. The schedule for each of the laboratory tests required by 1 or more targeted psoriasis therapies were taken, when possible, from the drug's labeling; otherwise, they were gathered by examination of the therapeutic protocol in the pivotal trials. ${ }^{40}$ Costs for laboratory tests were taken from their CPT codes. In addition to these laboratory tests, each patient was assumed to receive 4 physician visits per year related to the disease.

No previous economic analyses have indicated that adverse events significantly affect the cost-effectiveness of targeted therapies in psoriasis. However, the effect of the cost of 1 serious adverse event, pneumonia, was included to assess the potential importance of adverse events in relation to health care costs. Pneumonia incidence was taken from the prescribing information of each drug that has already entered the market and a metaanalysis of phase 3 trials for brodalumab. 26 Due to nonstandard terminology, the figure for each drug reflected the incidence of pneumonia, serious infection, or serious respiratory infection. In the case of apremilast, no mention of serious infection was found in the prescribing information, and so we assumed that it did not increase risk of pneumonia. Absolute rates, rather than placebo-adjusted rates, were used. A cost of $\$ 5,873$ per hospitalized case of pneumonia was used, based on Medicare reimbursement rates. ${ }^{41}$

\begin{tabular}{|c|c|c|c|c|c|c|c|}
\hline Treatment & Initiation Phase & Maintenance Phase & $\begin{array}{l}\text { Discount } \\
\text { from List } \\
\text { Price (\%) }\end{array}$ & $\begin{array}{l}\text { Unit Cost } \\
(\$)\end{array}$ & \begin{tabular}{|c|} 
Initiation \\
Period Cost \\
$(\$)$
\end{tabular} & \begin{tabular}{|c|} 
Monthly \\
Maintenance \\
Cost (\$)
\end{tabular} & \begin{tabular}{|c} 
Cost of \\
First Year of \\
Therapy (\$)
\end{tabular} \\
\hline Adalimumab (per $40 \mathrm{mg}$ ) & $80 \mathrm{mg}$ once & $40 \mathrm{mg}$ once every 2 weeks & 30 & 1,434 & $\begin{array}{c}14,361 \\
(4 \text { months })\end{array}$ & 2,868 & 37,305 \\
\hline Apremilast (per $30 \mathrm{mg}$ ) & $\begin{array}{l}\text { Increase dose by } 10 \mathrm{mg} \text { per } \\
\text { day to target dose of } 60 \mathrm{mg}\end{array}$ & $30 \mathrm{mg}$ twice a day & 20 & 34 & $\begin{array}{c}7,549 \\
(4 \text { months })\end{array}$ & 1,931 & 22,997 \\
\hline Brodalumab (per $210 \mathrm{mg}$ ) & $\begin{array}{l}210 \mathrm{mg} \text { once a week for } \\
3 \text { weeks }\end{array}$ & $210 \mathrm{mg}$ once every 2 weeks & 20 & 1,400 & $\begin{array}{c}9,800 \\
(3 \text { months })\end{array}$ & 2,800 & 35,000 \\
\hline Etanercept (per $50 \mathrm{mg}$ ) & $\begin{array}{l}50 \text { mg twice a week for } \\
12 \text { weeks }\end{array}$ & $50 \mathrm{mg}$ once a week & 30 & 717 & $\begin{array}{c}17,283 \\
\text { (3 months) }\end{array}$ & 2,868 & 43,095 \\
\hline Infliximab (per 100 mg) & $\begin{array}{l}5 \mathrm{mg} / \mathrm{kg} \text { at Weeks } 0,2 \text {, } \\
\text { and } 6\end{array}$ & $5 \mathrm{mg} / \mathrm{kg}$ once every 8 weeks & 30 & 779 & $\begin{array}{c}16,874 \\
(10 \text { weeks })\end{array}$ & 1,948 & 35,380 \\
\hline Ixekizumab (per 80 mg) & $\begin{array}{l}160 \mathrm{mg} \text { once, then } 80 \mathrm{mg} \\
\text { every } 2 \text { weeks for } 12 \text { weeks }\end{array}$ & $80 \mathrm{mg}$ once every 4 weeks & 40 & 2,681 & $\begin{array}{c}21,523 \\
\text { (3 months) }\end{array}$ & 2,681 & 45,652 \\
\hline Secukinumab (per $300 \mathrm{mg}$ ) & $\begin{array}{l}300 \mathrm{mg} \text { once a week for } \\
4 \text { weeks }\end{array}$ & $300 \mathrm{mg}$ once every 4 weeks & 40 & 2,439 & $\begin{array}{c}14,656 \\
\text { (3 months) }\end{array}$ & 2,439 & 36,607 \\
\hline $\begin{array}{l}\text { Ustekinumab } \\
\text { (70\% } 45 \mathrm{mg} / 30 \% 90 \mathrm{mg})\end{array}$ & $\begin{array}{l}45 \mathrm{mg} \text { at Weeks } 0 \text { and } 4 \\
(90 \mathrm{mg} \text { if }>100 \mathrm{~kg})\end{array}$ & $\begin{array}{l}45 \mathrm{mg} \text { once every } 12 \text { weeks } \\
(90 \mathrm{mg} \text { if }>100 \mathrm{~kg})\end{array}$ & 15 & 7,514 & $\begin{array}{c}26,072 \\
\text { (3 months) }\end{array}$ & 3,256 & 55,376 \\
\hline $\begin{array}{l}\text { Secondary therapy with } \\
\text { IL-17 only (per month) }\end{array}$ & N/A & N/A & N/A & 2,173 & $\begin{array}{c}8,824 \\
(1 \text { month }) \\
\end{array}$ & 2,173 & 32,731 \\
\hline $\begin{array}{l}\text { Secondary therapy with } \\
\text { IL-17 plus ustekinumab } \\
\text { (per month) }\end{array}$ & N/A & N/A & N/A & 2,381 & $\begin{array}{c}9,621 \\
(1 \text { month) }\end{array}$ & 2,381 & 35,817 \\
\hline $\begin{array}{l}\text { No pharmacotherapy } \\
\text { (per month) }\end{array}$ & N/A & N/A & N/A & 611 & N/A & 611 & N/A \\
\hline
\end{tabular}




\section{APPENDIX B Model Parameters and Distributions}

\begin{tabular}{|c|c|c|c|c|c|}
\hline Parameter & Base Value & Low Value & High Value & Distribution & Source \\
\hline Initial response, adalimumab & $\begin{array}{l}\text { PASI 90-100: } 0.372 \\
\text { - PASI 75-89: } 0.277 \\
\text { - PASI 50-74: } 0.169 \\
\text { - PASI <50: } 0.182\end{array}$ & $\begin{array}{l}\text { PASI 90-100: } 0.320 \\
\text { - PASI 75-89: } 0.232 \\
\text { - PASI 50-74: } 0.134 \\
\text { - PASI <50: } 0.145\end{array}$ & $\begin{array}{l}\text { PASI 90-100: } 0.422 \\
\text { - PASI 75-89: } 0.320 \\
\text { - PASI 50-74: } 0.202 \\
\text { - PASI <50: } 0.217\end{array}$ & Dirichlet & Network meta-analysis ${ }^{18}$ \\
\hline Initial response, apremilast & $\begin{array}{l}\text { - PASI 90-100: } 0.112 \\
\text { - PASI 75-89: } 0.194 \\
\text { - PASI 50-74: } 0.201 \\
\text { - PASI <50: } 0.493\end{array}$ & $\begin{array}{l}\text { - PASI 90-100: } 0.083 \\
\text { - PASI 75-89: } 0.156 \\
\text { - PASI 50-74: } 0.163 \\
\text { - PASI <50: } 0.433\end{array}$ & $\begin{array}{l}\text { - PASI 90-100: } 0.139 \\
\text { - PASI 75-89: } 0.230 \\
\text { - PASI 50-74: } 0.237 \\
\text { - PASI <50: } 0.551\end{array}$ & Dirichlet & Network meta-analysis ${ }^{18}$ \\
\hline Initial response, brodalumab & $\begin{array}{l}\text { - PASI 90-100: } 0.650 \\
\text { - PASI 75-89: } 0.213 \\
\text { - PASI 50-74: } 0.084 \\
\text { - PASI <50: } 0.053\end{array}$ & $\begin{array}{l}\text { - PASI 90-100: } 0.581 \\
\text { - PASI 75-89: } 0.174 \\
\text { - PASI 50-74: } 0.059 \\
\text { - PASI <50: } 0.033\end{array}$ & $\begin{array}{l}\text { - PASI 90-100: } 0.717 \\
\text { - PASI 75-89: } 0.251 \\
\text { - PASI 50-74: } 0.107 \\
\text { - PASI <50: } 0.071\end{array}$ & Dirichlet & Network meta-analysis ${ }^{18}$ \\
\hline Initial response, etanercept & $\begin{array}{l}\text { - PASI 90-100: } 0.220 \\
\text { - PASI 75-89: } 0.255 \\
\text { - PASI 50-74: } 0.203 \\
\text { - PASI < 50: } 0.322\end{array}$ & $\begin{array}{l}\text { - PASI 90-100: } 0.180 \\
\text { - PASI 75-89: } 0.212 \\
\text { - PASI 50-74: } 0.164 \\
\text { - PASI <50: } 0.274\end{array}$ & $\begin{array}{l}\text { - PASI 90-100: } 0.258 \\
\text { - PASI 75-89: } 0.296 \\
\text { - PASI 50-74: } 0.240 \\
\text { - PASI <50: } 0.369\end{array}$ & Dirichlet & Network meta-analysis ${ }^{18}$ \\
\hline Initial response, infliximab & $\begin{array}{l}\text { - PASI 90-100: } 0.598 \\
\text { - PASI 75-89: } 0.233 \\
\text { - PASI 50-74: } 0.100 \\
\text { - PASI <50: } 0.069\end{array}$ & $\begin{array}{l}\text { - PASI 90-100: } 0.532 \\
\text { - PASI 75-89: } 0.192 \\
\text { - PASI 50-74: } 0.073 \\
\text { - PASI <50: } 0.047\end{array}$ & $\begin{array}{l}\text { - PASI 90-100: } 0.662 \\
\text { - PASI 75-89: } 0.272 \\
\text { - PASI 50-74: } 0.125 \\
\text { - PASI <50: } 0.090\end{array}$ & Dirichlet & Network meta-analysis ${ }^{18}$ \\
\hline Initial response, ixekizumab & $\begin{array}{l}\text { - PASI 90-100: } 0.695 \\
\text { - PASI 75-89: } 0.194 \\
\text { - PASI 50-74: } 0.071 \\
\text { - PASI <50: } 0.040\end{array}$ & $\begin{array}{l}\text { - PASI 90-100: } 0.624 \\
\text { - PASI 75-89: } 0.156 \\
\text { - PASI 50-74: } 0.048 \\
\text { - PASI <50: } 0.023\end{array}$ & $\begin{array}{l}\text { - PASI 90-100: } 0.764 \\
\text { - PASI 75-89: } 0.230 \\
\text { - PASI 50-74: } 0.092 \\
\text { - PASI <50: } 0.055\end{array}$ & Dirichlet & Network meta-analysis ${ }^{18}$ \\
\hline Initial response, secukinumab & $\begin{array}{l}\text { - PASI 90-100: } 0.503 \\
\text { - PASI 75-89: } 0.260 \\
\text { - PASI 50-74: } 0.130 \\
\text { - PASI <50: } 0.107\end{array}$ & $\begin{array}{l}\text { - PASI 90-100: } 0.443 \\
\text { - PASI 75-89: } 0.216 \\
\text { - PASI 50-74: } 0.099 \\
\text { - PASI <50: } 0.079\end{array}$ & $\begin{array}{l}\text { - PASI 90-100: } 0.562 \\
\text { - PASI 75-89: } 0.302 \\
\text { - PASI 50-74: } 0.159 \\
\text { - PASI <50: } 0.133\end{array}$ & Dirichlet & Network meta-analysis ${ }^{18}$ \\
\hline Initial response, ustekinumab & $\begin{array}{l}\text { - PASI 90-100: } 0.420 \\
\text { - PASI 75-89: } 0.274 \\
\text { - PASI 50-74: } 0.155 \\
\text { - PASI <50: } 0.151\end{array}$ & $\begin{array}{l}\text { - PASI 90-100: } 0.365 \\
\text { - PASI 75-89: } 0.229 \\
\text { - PASI 50-74: } 0.121 \\
\text { - PASI <50: } 0.118\end{array}$ & $\begin{array}{l}\text { - PASI 90-100: } 0.473 \\
\text { - PASI 75-89: } 0.317 \\
\text { - PASI 50-74: } 0.187 \\
\text { - PASI <50: } 0.182\end{array}$ & Dirichlet & Network meta-analysis ${ }^{18}$ \\
\hline $\begin{array}{l}\text { Discontinuation rate (\%), } \\
\text { adalimumab }\end{array}$ & $\begin{array}{l}\text { - Year 1: } 27 \\
\text { - Year >1: } 15\end{array}$ & $\begin{array}{l}\text { - Year 1: } 20 \\
\text { - Year > 1: } 11.25\end{array}$ & $\begin{array}{l}\text { - Year 1: } 34 \\
\text { - Year >1: } 16.5\end{array}$ & Beta & $\begin{array}{l}\text { Feldman (2015),26 } \\
\text { Gniadecki (2015)27 }\end{array}$ \\
\hline $\begin{array}{l}\text { Discontinuation rate (\%), } \\
\text { apremilast }\end{array}$ & $\begin{array}{l}\text { - Year 1: } 35 \\
\text { - Year > 1: } 15 \\
\end{array}$ & $\begin{array}{l}\text { - Year 1: } 30 \\
\text { - Year > 1: } 11.25 \\
\end{array}$ & $\begin{array}{l}\text { - Year 1: } 41 \\
\text { - Year > 1: } 16.5 \\
\end{array}$ & Beta & $\begin{array}{l}\text { Estimate based on Feldman } \\
(2015),{ }^{26} \text { Gniadecki }(2015)^{27}\end{array}$ \\
\hline $\begin{array}{l}\text { Discontinuation rate (\%), } \\
\text { brodalumab }\end{array}$ & $\begin{array}{l}\text { - Year 1: } 16 \\
\text { - Year > 1: } 5\end{array}$ & $\begin{array}{l}\text { - Year 1: } 12 \\
\text { - Year > 1: } 2.5\end{array}$ & $\begin{array}{l}\text { - Year 1: } 20 \\
\text { - Year > 1: } 10\end{array}$ & Beta & $\begin{array}{l}\text { Estimate based on Feldman } \\
(2015),{ }^{26} \text { Gniadecki }(2015)^{27}\end{array}$ \\
\hline $\begin{array}{l}\text { Discontinuation rate (\%), } \\
\text { etanercept }\end{array}$ & $\begin{array}{l}\text { - Year 1: } 35 \\
\text { - Year > 1: } 15 \\
\end{array}$ & $\begin{array}{l}\text { - Year 1: } 30 \\
\text { - Year > 1: } 11.25\end{array}$ & $\begin{array}{l}\text { - Year 1: } 40 \\
\text { - Year > 1: } 16.5\end{array}$ & Beta & $\begin{array}{l}\text { Feldman (2015), } 26 \\
\text { Gniadecki (2015)27 }\end{array}$ \\
\hline $\begin{array}{l}\text { Discontinuation rate (\%), } \\
\text { infliximab }\end{array}$ & $\begin{array}{l}\text { - Year 1: } 27 \\
\text { - Year > 1: } 15\end{array}$ & $\begin{array}{l}\text { - Year 1: } 25 \\
\text { - Year >1: } 11.25\end{array}$ & $\begin{array}{l}\text { - Year 1: } 35 \\
\text { - Year >1: } 16.5\end{array}$ & Beta & $\begin{array}{l}\text { Estimate based on Feldman } \\
(2015),{ }^{26} \text { Gniadecki }(2015)^{27}\end{array}$ \\
\hline $\begin{array}{l}\text { Discontinuation rate (\%), } \\
\text { ixekizumab }\end{array}$ & $\begin{array}{l}\text { - Year 1: } 16 \\
\text { - Year > 1: } 5\end{array}$ & $\begin{array}{l}\text { - Year 1: } 12 \\
\text { - Year > 1: } 2.5\end{array}$ & $\begin{array}{l}\text { - Year 1: } 20 \\
\text { - Year >1: } 10\end{array}$ & Beta & $\begin{array}{l}\text { Estimate based on Feldman } \\
(2015),{ }^{26} \text { Gniadecki }(2015)^{27}\end{array}$ \\
\hline $\begin{array}{l}\text { Discontinuation rate (\%), } \\
\text { secukinumab }\end{array}$ & $\begin{array}{l}\text { - Year 1: } 16 \\
\text { - Year > 1: } 5 \\
\end{array}$ & $\begin{array}{l}\text { - Year 1: } 12 \\
\text { - Year > 1: } 2.5 \\
\end{array}$ & $\begin{array}{l}\text { - Year 1: } 20 \\
\text { - Year > 1: } 10 \\
\end{array}$ & Beta & $\begin{array}{l}\text { Estimate based on Feldman } \\
(2015), 26 \text { Gniadecki }(2015)^{27}\end{array}$ \\
\hline $\begin{array}{l}\text { Discontinuation rate (\%), } \\
\text { ustekinumab }\end{array}$ & $\begin{array}{l}\text { - Year 1: } 16 \\
\text { - Year > 1: } 5\end{array}$ & $\begin{array}{l}\text { - Year 1: } 12 \\
\text { - Year > 1: } 2.5\end{array}$ & $\begin{array}{l}\text { - Year 1: } 20 \\
\text { - Year > 1: } 10\end{array}$ & Beta & $\begin{array}{l}\text { Feldman }(2015), 26 \\
\text { Gniadecki }(2015)^{27}\end{array}$ \\
\hline $\begin{array}{l}\text { Discontinuation rate (\%), } \\
\text { secondary to no treatment }\end{array}$ & 10 & 5 & 15 & Beta & $\begin{array}{l}\text { Estimate based on Feldman } \\
(2015),{ }^{26} \text { Gniadecki }(2015)^{27}\end{array}$ \\
\hline $\begin{array}{l}\text { Drug cost (\$), adalimumab } \\
\text { (per } 40 \mathrm{mg} \text { ) }\end{array}$ & $1,433.98$ & $1,147.18$ & $1,720.78$ & Normal & WAC minus discount ${ }^{32}$ \\
\hline $\begin{array}{l}\text { Drug cost (\$), apremilast } \\
\text { (per } 30 \mathrm{mg})\end{array}$ & 34.48 & 27.58 & 41.38 & Normal & WAC minus discount 32 \\
\hline $\begin{array}{l}\text { Drug cost (\$), brodalumab } \\
\text { (per } 210 \mathrm{mg})\end{array}$ & $1,400.00$ & $1,129.00$ & $1,680.00$ & Normal & WAC minus discount ${ }^{32}$ \\
\hline $\begin{array}{l}\text { Drug cost (\$), etanercept } \\
(\text { per } 50 \mathrm{mg})\end{array}$ & 717.11 & 573.69 & 860.53 & Normal & WAC minus discount ${ }^{32}$ \\
\hline
\end{tabular}




\section{APPENDIX B Model Parameters and Distributions (continued)}

\begin{tabular}{|c|c|c|c|c|c|}
\hline Parameter & Base Value & Low Value & High Value & Distribution & Source \\
\hline $\begin{array}{l}\text { Drug cost (\$), infliximab } \\
\text { (per } 100 \mathrm{mg} \text { ) }\end{array}$ & 779.20 & 623.36 & 935.04 & Normal & WAC minus discount ${ }^{32}$ \\
\hline $\begin{array}{l}\text { Drug cost (\$), ixekizumab } \\
\text { (per } 80 \mathrm{mg} \text { ) }\end{array}$ & $2,681.40$ & $2,145.12$ & $3,217.68$ & Normal & WAC minus discount ${ }^{32}$ \\
\hline $\begin{array}{l}\text { Drug cost (\$), secukinumab } \\
\text { (per } 300 \mathrm{mg})\end{array}$ & $2,438.74$ & $2,145.12$ & $2,926.49$ & Normal & WAC minus discount ${ }^{32}$ \\
\hline $\begin{array}{l}\text { Drug cost (\$), ustekinumab } \\
\text { (per } 45 \mathrm{mg} \text { ) }\end{array}$ & $7,514.19$ & $6,011.35$ & $9,017.03$ & Normal & WAC minus discount ${ }^{32}$ \\
\hline $\begin{array}{l}\text { Laboratory cost (\$), latent } \\
\text { TB screen }\end{array}$ & 22.56 & 20.30 & 24.82 & Normal & $\begin{array}{l}\text { CMS fee schedule, } 2016 \\
(71010)^{41}\end{array}$ \\
\hline $\begin{array}{l}\text { Laboratory cost (\$), active } \\
\text { TB screen }\end{array}$ & 7.88 & 7.09 & 8.67 & Normal & $\begin{array}{l}\text { CMS fee schedule, } 2016 \\
(86580)^{41}\end{array}$ \\
\hline $\begin{array}{l}\text { Laboratory cost (\$), complete } \\
\text { blood count (updated to } 2016 \\
\text { U.S. dollars) }\end{array}$ & 19.11 & 17.20 & 21.02 & Normal & Hankin $(2005)^{42}$ \\
\hline $\begin{array}{l}\text { Laboratory cost (\$), } \\
\text { hepatitis B screen (updated } \\
\text { to } 2016 \text { U.S. dollars) }\end{array}$ & 17.29 & 15.56 & 19.02 & Normal & Eckman $(2011)^{43}$ \\
\hline $\begin{array}{l}\text { Laboratory cost (\$), liver } \\
\text { function test (updated to } \\
2016 \text { U.S. dollars) }\end{array}$ & 19.11 & 17.20 & 21.02 & Normal & Hankin $(2005)^{42}$ \\
\hline $\begin{array}{l}\text { Laboratory cost }(\$) \text {, renal } \\
\text { function test (updated to } \\
2016 \text { U.S. dollars) }\end{array}$ & 20.88 & 18.79 & 22.97 & Normal & Hankin $(2005)^{42}$ \\
\hline $\begin{array}{l}\text { Clinic visit (\$) (updated to } \\
2016 \text { U.S. dollars) }\end{array}$ & 87.90 & 79.11 & 96.69 & Normal & Hankin $(2005)^{42}$ \\
\hline $\begin{array}{l}\text { In-clinic subcutaneous } \\
\text { injection (\$) }\end{array}$ & 25.44 & 20.35 & 30.53 & Normal & $\begin{array}{l}\text { CMS fee schedule, } 2016 \\
(96372)^{41}\end{array}$ \\
\hline $\begin{array}{l}\text { Intravenous administration } \\
(\$)\end{array}$ & 164.54 & 131.63 & 197.45 & Normal & $\begin{array}{l}\text { CMS fee schedule, } 2016 \\
(96413+96415)^{41}\end{array}$ \\
\hline
\end{tabular}

